\title{
Erratum to: Case study on municipal solid waste management in Vavuniya township: practices, issues and viable management options
}

\author{
Ranil K. A. Kularatne
}

Published online: 8 August 2014

(C) Springer Japan 2014

\section{Erratum to: J Mater Cycles Waste Manag \\ DOI 10.1007/s10163-013-0225-7}

The author would like to correct the errors in the publication of the original article. The corrected details are given below for your reading.

The last paragraph under the sub-topic "Waste generation and composition" (Results and discussion section of the article) should be read as follows.

Nevertheless, the public surveys revealed that household waste on average comprises $80-90 \%$ organic (biodegradable) material, which is higher than the organic content in the mixed MSW collected by the UC (Fig. 3). This finding confirms that addition of other material reduces the organic material content [4].

Also under the sub-topic "Landfilling" in "Legislation and current MSW practices" (Results and discussion section of the paper), the JICA funded engineered Moon Plains landfill is situated within the Nuwara Eliya District (not Kandy District).

The author regrets for the errors.

The online version of the original article can be found under doi:10.1007/s10163-013-0225-7.

R. K. A. Kularatne $(\bowtie)$

GreenTec Consultants (Pvt.) Limited and Environmental

Foundation Limited (EFL), Colombo 5, Srilanka

e-mail: RanilKularatne@yahoo.com.au 